\title{
Excess incidence of asthma among Finnish cleaners employed in different industries
}

\author{
A. Karjalainen*, R. Martikainen*, J. Karjalainen\#, T. Klaukka", K. Kurppa*
}

Excess incidence of asthma among Finnish cleaners employed in different industries. A. Karjalainen, R. Martikainen, J. Karjalainen, T. Klaukka, K. Kurppa. C ERS Journals Ltd 2002.

ABSTRACT: The incidence and risk of asthma among female cleaners employed in different industries was explored. An increased risk of asthma has been associated with the cleaning profession, in some but not all studies.

All Finnish females employed as cleaners and all those employed in administrative work were followed for asthma incidence through a record linkage in 1986-1998. An individual was defined as an "incident case of asthma" if they received rights for special reimbursement of asthma medication from the national health insurance or were recognized as having occupational asthma. Age-adjusted relative risks (RR) were estimated for cleaners in comparison with those employed in administrative work.

There were 2,414 and 5,235 cases of asthma among the cleaners and administrative workers, respectively. The RR was 1.50 (95\% confidence interval (CI) $1.43-1.57)$ in cleaners. The risk was increased in cleaners working in nearly all major sectors of economic activity, but cleaners employed by companies concerned with the manufacture of basic metals (RR 2.47; 95\% CI 1.68-3.64) and food products (RR 2.19; 95\% CI 1.69-2.85) had the highest risk. Only 25 of the "cases of asthma" among cleaners had been recognized as being occupational asthma.

It could be concluded that cleaners have an increased risk of persistent adult-onset asthma. Factors inherent to the environment where cleaning is performed or differences in the cleaning agents used may explain the observed differences between industries. Eur Respir J 2002; 19: 90-95.
*Finnish Institute of Occupational Health, Dept of Epidemiology and

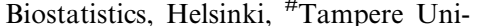
versity Hospital, Dept of Respiratory Medicine, Tampere and "Social Insurance Institution, Helsinki, Finland.

Correspondence: A. Karjalainen, Finnish Institute of Occupational Health, Topeliuksenkatu $41 \mathrm{aA}, \quad$ FIN-00250 Helsinki, Finland.

Fax: 358947472423

Keywords: Asthma

cleaners

epidemiology

incidence

risk

Received: January 32001

Accepted after revision August 212001

The study was financially supported by the Rehabilitation Funds of the Finnish Social Insurance Institution.
Cleaning consists of dusting, washing and polishing surfaces, walls and floors as well as disposing of waste and waste water [1]. It is carried out in offices, public and commercial buildings, factories and homes. Consequently cleaners are exposed to various indoor allergens in dusts and chemical components of soaps, detergents, disinfectants, porcelain cleaners, scouring powders, wax removers and strippers, solvents, pesticides and drain cleaners [1]. An increased risk of asthma has been associated with work as a cleaner in some $[2,3]$ but not all studies investigating workrelated risks of asthma $[4,5]$. Occasional case reports have described occupational asthma due to specific sensitization to components of detergents $[6,7]$ or disinfectants [8] but overall the determinants of the risk of asthma in cleaners remain unknown.

The variation in asthma incidence among cleaners employed in different sectors of economic activity might suggest hypotheses on determinants of asthma risk among cleaners. Finland provides a rather unique opportunity to study variation of asthma incidence in the employed population. In Finland, much of the cost of asthma medication is reimbursed from a national health insurance scheme that covers the entire Finnish population. The prerequisite for special reimbursement is that rigorous clinical criteria for persistent asthma are fulfilled and recorded in a special certificate that is perused by experts of the national Social Insurance Institution (SII). As a consequence, patients with well established asthma become registered in a national register. A personal identification code allows for supplementation of the register information with facts on employment and occupation from the Finnish Population Census. Such a record linkage allows for comparison of asthma incidence in various occupational groups in a register that contains tens-of-thousands of incident cases of adult onset asthma

A registry based nationwide follow-up study was performed in 1986-1998. The aim was to estimate the risk of asthma among cleaners and to explore the variation of risk between cleaners employed in different industries.

\section{Material and methods}

\section{Study population}

All employed female cleaners and administrative workers were followed for asthma incidence during 1986-1998. Three cohorts of cleaners and three cohorts of administrative workers identified from three most recent population censuses were included. 
Table 1. - Number of cases and incidence of asthma by age in female cleaners and administrative workers

\begin{tabular}{|c|c|c|c|c|c|c|}
\hline \multirow[t]{2}{*}{ Age yrs } & \multicolumn{3}{|c|}{ Cleaners } & \multicolumn{3}{|c|}{ Administrative workers } \\
\hline & Cases & Population $^{\#}$ & Incidence $\cdot 1000 \cdot \mathrm{yr}^{-1}$ & Cases & Population $^{\#}$ & Incidence $\cdot 1000 \cdot \mathrm{yr}^{-1}$ \\
\hline $25-39$ & $562(23)$ & $18134(34)$ & $2.26(2.08-2.46)$ & $2141(41)$ & $104250(51)$ & $1.53(1.47-1.60)$ \\
\hline $40-49$ & $868(36)$ & $18977(35)$ & $3.48(3.25-3.71)$ & $1837(35)$ & $66857(33)$ & $2.16(2.06-2.26)$ \\
\hline $50-59$ & $984(41)$ & $16597(31)$ & $4.44(4.17-4.73)$ & $1257(24)$ & 31644 (16) & $3.15(2.98-3.33)$ \\
\hline All & $2414(100)$ & $53708(100)$ & $3.35(3.22-3.49)$ & $5235(100)$ & $202751(100)$ & $1.98(1.92-2.03)$ \\
\hline
\end{tabular}

Data are presented as $\mathrm{n}(\%)$ or incidence $\left(95 \%\right.$ confidence interval). ${ }^{*}$ : population refers to the arithmetic mean of the population under follow-up in the 1985, 1990 and 1995 censuses.

All females employed as cleaners and all those employed in administrative, managerial and clerical work in Finland, without pre-existing asthma and aged 25-59 yrs in December 31 1985, 1990 and 1995 were followed for asthma during the years 1986-1990, 1991-1995 and 1996-1998, respectively. There was on average 54,000 female cleaners and 203,000 administrative workers in the three census cohorts (table 1).

The follow-up was performed using the unique personal identification code through two national registries: the Medication Reimbursement Register of the SII of Finland and the Finnish Register of Occupational Diseases (FROD). Duplicate notifications between the registries were identified using the personal identification code. The matching of the registries to the population census according to the personal identification code failed in only $0.01 \%$ of cases. For each follow-up period the cases and personyrs were calculated according, to the occupation and sector of economic activity the individual held at the start of the follow-up. An individual could contribute to the person-yrs of several follow-up periods, provided they had not been defined as an incident case of asthma before the start of the followup period and were still employed as a cleaner or as an administrative worker at the start of the follow-up period. Therefore the number of individuals under follow-up is given as an average of the three follow-up periods and not as an absolute number of the different individuals followed. The occupation was known for $99 \%$ of the employed in each of the three censuses.

The study protocol was approved by the ethical committees of the participating institutions.

\section{Definition and ascertainment of cases}

Incident cases of asthma were collected from the Medication Reimbursement Register of the SII. In Finland, asthma is one of the chronic diseases for which the medication can be reimbursed at a higher than ordinary level. To receive the compensation the patient has to apply for the entitlement from the SII by providing the application with a medical certificate written by a chest physician (for children a paediatrician). For compensation to be granted, the disease has to fulfil the diagnostic and severity criteria of asthma, including objective data of reversible bronchial obstruction and a persistent pattern of disease (table 2). The health insurance which includes a drug-reimbursement system covers the entire Finnish population and consequently all Finnish patients with asthma fulfilling the criteria discussed earlier are identifiable in the register. The only exception concerns patients with recognized occupational asthma who receive a full compensation for medication from the Statutory Accident Insurance. The latter group of patients are centrally registered by the Finnish Institute of Occupational Health. The recognition of occupational asthma necessitates a diagnosis of asthma made by a chest physician and individual evidence of a causal association between the individual's specific workplace exposure and the disease.

Individuals were defined as an asthma case if they received rights for reimbursement of asthma medication from the SII or were notified as having occupational asthma by FROD. The date of the application (SII) or the date of the notification report (FROW was used as a proxy for the date of diagnosis.

\section{Assessment of the reliability of the diagnoses}

Granted reimbursement of medication has previously been used in some studies on the epidemiology of asthma [9, 10] but validation of this case-ascertainment approach has not been published. The accuracy of the asthma diagnosis, in a sample of adult cases identified in the SII register, was therefore assessed. The analysis was carried out in a representative sample of the Finnish population $(n=12,936)$ examined by SII and the National Research Centre

Table 2. - The diagnostic criteria of asthma for granted special medication reimbursement from the Social Insurance Institution

A typical history, clinical features and course of asthma must be documented in the medical certificate and the following physiological criteria are applied

At least one of the following criteria

A variation of $\geqslant 20 \%$ in diurnal PEF recording (reference to maximal value)

An increase of $\geqslant 15 \%$ in PEF of FEV 1 with $\beta_{2}$-agonist A decrease of $\geqslant 15 \%$ in PEF or FEV1 in exercise testing And

A continuing regular use of asthma medication which has lasted for 6 months at the time of the decision

PEF: peak expiratory flow rate. In addition to the percentage limits given, an absolute limit value of $\geqslant 50 \mathrm{~L} \cdot \mathrm{min}^{-1}$ is used; FEV1: forced expiratory volume in one second. In addition to the percentage limits given, an absolute limit value of $\geqslant 0.15 \mathrm{~L}$ is used. 
for Welfare and Health [11]. There were 205 individuals who had received reimbursement rights for asthma medication in 1986-1998 and were aged 25-59 yrs at the time when the rights were granted. Data from the SII medical certificates was analysed and, if the medical certificate was incomplete, data from hospital records (with the patient's permission). A complete medical certificate or the case history from the hospital records was available for all the 205 cases. The diagnostic criteria of table 2 were fulfilled in $183(89 \%)$ of the cases and in another 20 cases $(10 \%)$ a physician diagnosis of asthma had been made on the basis of other clinical data (most often a history of typical asthma symptoms together with observed bronchial hyperresponsiveness). In addition, there were two cases of post-tuberculotic respiratory problems in which asthma was clearly not present. Of the 203 patients with asthma, 20 also had another chronic pulmonary disease (18 patients had chronic obstructive pulmonary disease (COPD) and two had chronic symptomatic bronchiectasis). The assessment of the negative-predictive value of granted reimbursement rights versus asthma fulfilling criteria of table 2 would have necessitated full-scale clinical asthma investigations for a large sample of individuals from the general population sample. This was not done.

\section{Classification of occupation of the individual and economic activity of the employer}

Information on the professional status, current occupation and economic activity of the employer is recorded for every employed person in the Finnish Population Census. The occupational code is an extended classification of the International Standard Classification of Occupations published by the International Labour Office in 1958. The economic activity code is an extended classification of the Standard Industrial Classification of all Economic Activities published by the United Nations in 1968.

The occupational code of cleaners includes both cleaners and head cleaners, which could not be separated from each other. Cleaners were also divided into subcohorts according to the economic activity of their employer.

Information on occupation was cross-sectional from the time of the census. Those aged $<25 \mathrm{yrs}$ were not followed, because change of occupation and migration between education and working life make the employment status and occupation at the start of follow-up less reliable indicators of the occupational status during the 5-yr follow-up, especially for administrative workers. Similarly those aged $>59$ yrs were not followed, because most of those employed at the start of the follow-up would not have stayed employed until the end of follow-up. In the age range included, $21 \%$ of cleaners with asthma and $14 \%$ of administrative workers with asthma and employed in the population censuses, both before and after the diagnosis, had changed their occupation during the 5 -yr follow-up. The cross-sectional information on occupation does not allow for an estimation on whether these changes had occurred before or after the date of granted reimbursement nights for asthma medication.

\section{Statistical analyses}

The incidence rate for each occupation/economic activity group was calculated by summing up the cases and person-yrs from the three census cohorts and dividing the total number of cases by the accumulated person-yrs under follow-up in that group. Incidencerate ratios (relative risks (RR)) and their 95\% confidence intervals (CI) for cleaners were estimated by a log-linear model. Age at start of follow-up (25-39, 40-49, 50-59 yrs), occupation and industry of the employer were included in the model. Those employed in administrative, managerial and clerical work were used as a reference group. Interaction between age and occupation was not significant $(\mathrm{p}=0.08)$ and was not included in the model. SAS software was used in the analyses.

Adjustment for calendar period (follow-up period) did not influence the occupation-specific RR and was not included in the model. Separate analyses were also performed using only the lower administrative and clerical employees (secretaries, office clerks, bookkeepers and similar occupations) as a reference. In this reference group, the total incidence rate of asthma differed $<0.5 \%$ and each of the age-category specific incidence rates of asthma $<2 \%$ from those in administrative workers in general and consequently the RR did not significantly change. Only the results based on the reference group of all administrative, clerical and managerial work are presented. In this reference group, $49 \%$ were office clerks or other clerks, $23 \%$ secretaries or typists, $18 \%$ managers or other managerial workers and $10 \%$ bookkeepers or related workers.

The attributable fraction among the exposed, i.e. the work-related fraction of asthma among cleaners, was estimated according to the formula given by RothMAN and GREENLAND [12].

\section{Results}

There were 2,414 and 5,235 cases of asthma among the female cleaners and administrative workers, respectively. The annual incidence rate of asthma was $3.4 \cdot 1000^{-1}$ among cleaners and $2.0 \cdot 1000^{-1}$ among administrative workers. The incidence rate increased with age in both cleaners and administrative workers (table 3). The age-adjusted RR was 1.50 (95\% CI 1.43-1.57) in cleaners. Based on the risk estimate, the work-related attributable fraction of asthma among cleaners was 33\% (95\% CI 30-36\%).

The age-adjusted risk was significantly increased in cleaners working in nearly all major industrial sectors (table 3 ). Cleaners employed by companies concerned with the manufacture of basic metals and food products had the highest risk. Of the 2,414 cases of asthma among cleaners during the follow-up period, 25 had been recognized as occupational asthma. The causative agents of these were quite 
Table 3. - Relative risk (RR) of asthma among employed female cleaners by industry in 1986-1998

\begin{tabular}{llcrr}
\hline Code & \multicolumn{1}{c}{ Industry } & Population & N & RR (95\% CI) \\
\hline Administrative, managerial and clerical work & & 202751 & 5235 & 1.00 ref \\
Cleaners, total & & 53708 & 2414 & $1.50(1.48-1.57)$ \\
15 & Manufacture of food products, etc. & 583 & $2.19(1.69-2.85)$ \\
20 & Manufacture of wood and wood products & 493 & $1.69(1.15-2.48)$ \\
21 & Manufacture of pulp, paper and paper products & 1090 & 26 & $1.78(1.38-2.29)$ \\
24 & Manufacture of chemicals and chemical products & 374 & 60 & $1.71(1.10-2.65)$ \\
27 & Manufacture of basic metals & 344 & $2.47(1.68-3.64)$ \\
29 & Manufacture of other machinery and equipment & 730 & $1.33(0.93-1.91)$ \\
40 & Electricity, gas and water supply & 572 & 30 & $1.36(0.92-2.01)$ \\
45 & Construction & 1451 & 25 & $1.62(1.28-2.04)$ \\
51 & Whole sale trade etc. & 361 & $1.82(1.19-2.80)$ \\
52 & Retail trade etc. & 1597 & 21 & $1.41(1.12-1.79)$ \\
55 & Hotels and restaurants & 1517 & 56 & $1.25(0.96-1.63)$ \\
60 & Land transport & 870 & 49 & $1.70(1.28-2.25)$ \\
64 & Post and telecommunications & 1143 & 51 & $1.39(1.05-1.83)$ \\
65 & Financial intermediation & 733 & 31 & $1.25(0.88-1.78)$ \\
70 & Real estate activities & 4998 & 243 & $1.70(1.49-1.93)$ \\
747 & Cleaning companies & 9390 & 348 & $1.44(1.30-1.60)$ \\
75 & Public administration and defence & 2495 & 116 & $1.49(1.24-1.79)$ \\
80 & Education & 7955 & 358 & $1.41(1.27-1.57)$ \\
85 & Health and social work & 9473 & 424 & $1.51(1.36-1.66)$ \\
91 & Activities of membership organizations & 926 & 25 & $0.87(0.59-1.29)$ \\
92 & Recreational, cultural and sporting activities & 1075 & 47 & $1.43(1.07-1.90)$ \\
\hline
\end{tabular}

Only industries with $>20$ cases among cleaners are presented. CI: confidence interval. ${ }^{\top}$ : arithmetic mean of population under follow-up in 1985, 1990 and 1995 censuses; ${ }^{\#}$ : both industry $(\mathrm{p}<0.001)$ and age $(\mathrm{p}<0.001)$ were significant predictors of asthma risk in the log-linear model and overall significance of the model was $<0.001$.

variable, there were five cases caused by flour dust, three cases caused by acrylates and two cases caused by isocyanates, detergents, ethanolamines and metal compounds.

\section{Discussion}

A significantly elevated RR of 1.5 for adult-onset asthma in female cleaners as compared to female administrative workers was found. A similar magnitude of risk was reported for cleaners aged 20-44 yrs in most of the countries participating in the European Community Respiratory Health Survey [2] and for cleaners aged 20-54 yrs in a case-control study in Singapore [3]. Somewhat smaller studies in Sweden [4] and New Zealand [5] found risk estimates around or below unity. An increased prevalence of asthma was also recently found among Spanish cleaners as compared to office workers [13]. The excess was primarily related to the cleaning of private homes. There are not a numerous number of cleaners employed as private-home cleaners, in Finland. In the present study such cleaners are included in the industrial branches of cleaning companies (as employees or self-employed workers) or health and social work if employed in the municipal cleaning service of elderly people. Within these two branches, employing the largest number of cleaners, those cleaning private homes cannot be separated from other cleaners.

Different definitions for asthma were used in the earlier mentioned studies, and direct comparison of the results is difficult. In the present study, the case ascertainment was carried out through two national registries which rely on diagnoses made by chest physicians based on clinical or physiological criteria and representing a persistent form of asthma. This definition of asthma, i.e. clinical assessment, is the standard which is used to validate the other definitions used in epidemiological studies [14]. The examination of the asthma diagnoses (methods section) indicates that the positive-predictive value of the definition is very high as compared to the definitions of asthma that have been used in most epidemiological studies. Such a definition is preferred in aetiological studies [14]. As the level of reimbursement of medication costs is relatively high ( $75 \%$ of total costs) it is also likely that all those who fulfil the criteria are registered. Conversely, the present definition is more restrictive than most other definitions of asthma, as it only includes cases with persistent asthma. Consequently the results apply only to occupational risk and incidence of persistent asthma.

The results indicate that the adverse public health impact of work-related factors in adult-onset asthma in cleaners and the potential for prevention are large. Cleaners account for $~ 5 \%$ of all employed females in Finland. An average of 190 annual-incident cases of persistent asthma were observed in this population during the follow-up. The observed 1.5 -fold risk of asthma means that approximately one-third of these cases may represent occupationally-derived asthma. Nevertheless the risk and the attributable fraction may still have been underestimated in the present study because a complete absence of harmful occupational exposure did not occur in the reference occupation (e.g. exposure to paper dust, emissions from office equipment or other impurities due to poor 
ventilation). Change of job due to respiratory symptoms is frequent before the diagnosis of asthma and may also have biased the risk estimates towards unity [15].

Register-linkage studies have acknowledged weaknesses [16]. Firstly, the information on exposures is often crude and misclassification may be difficult to prevent. Such errors are, however, usually nonsystematic and do not lead to false-positive associations. Secondly, when extensive data are linked, very small group differences give low $p$-values. An illustrative example is the interaction between age and exposure in the study. The interaction was nearly significant $(\mathrm{p}=0.08)$, while the actual differences in the RR of asthma in cleaners in the 25-39, 40-49 and 50-59 yrs age categories were only minor: $1.5,1.6$ and 1.4 respectively. Therefore it seems unlikely that age was an effect modifier. Thirdly, registers do not provide enough information on confounders. Cleaners have, on average, a lower socioeconomic status than administrative workers. Such an association could introduce confounding due to lifestyle factors and possibly result in overestimation of the work-related risk. A separate analysis using lower-level administrative workers as a reference group did not indicate such confounding of the work-related risk estimates.

Only $25(1 \%)$ of the 2,414 cases of asthma in female cleaners had been recognized as occupational asthma. The causative agents of these cases indicate exposures mostly inherent to the type of industry. The industryspecific RR observed in the present study, indicate that there are differences in the level of risk across the industries. Cleaners employed in the food processing and manufacture of basic metals industries had a higher risk than that of cleaners in general. These may relate to industry-specific exposures to allergens or other specific factors. Nevertheless, an increased risk of asthma was observed among cleaners regardless of the economic activity of the employer. This suggests that exposure to allergens or nonspecific irritants inherent to cleaning work may also be important determinants for the risk for asthma in cleaners. Of the specific industries studied, the incidence of asthma in cleaners did not significantly increase in membership organizations (i.e. employer or trade unions, religious organizations or cultural organizations). This finding may be due to chance and the relatively low number of cleaners employed in such organizations.

Preliminary findings from the European Community Respiratory Health Survey indicate that atopy is less common among cleaners with asthma than among administrative workers with asthma [17]. Irritantinduced asthma has also been described after several episodes rather than a single episode of exposure in pulp-mill workers [18] and the concept of "low dose reactive airways dysfunction syndrome" has been introduced [19]. Exposure to nonspecific dusts and vapours has also been associated with an increased risk of asthma $[4,20]$. Yet, the relevance of any of the associations discussed earlier for asthma in cleaners remains open. Interestingly, it was found that the incidence of asthma increased similarly with age between cleaners and administrative workers. This may indirectly suggest that the observed effect is not related to duration of employment as a cleaner.

To conclude, strong evidence that working as a cleaner is associated with an increased risk of adultonset persistent asthma was found. The results indicate that part of the explanation may be related to exposures inherent to the environment where cleaning is performed or to differences in the use of cleaning agents across the industries, while there also seems to be an overall excess of asthma in general for those working as a cleaner.

Acknowledgements. The authors are indebted to K. Toivola and T. Pitkonen of the Finnish Social Insurance Institution, M. Johnson of Statistics Finland, and A. Savela of the Finnish Register of Occupational Diseases for their assistance in building the data files.

\section{References}

1. Messing K. Indoor cleaning services. In: Stellman JM, ed. Encyclopaedia of Occupational Health and Safety 4th Edition. Geneva, International Labour Office, 1998; pp. 100.2-100.5.

2. Kogevinas M, Anto JM, Soniano JB, Toblas A, Bumey P. Occupational asthma in Europe and other industrialised areas: a population-based study. Lancet 1999; 353: 1750-1754.

3. Ng TP, Hong CY, Goh LG, Wong NIL, Koh KTC, Ling SL. Risk of asthma associated with occupations in a community-based case-control study. Am J Ind Med 1994; 25: 709-718.

4. Toren K, Balder B, Brisman J, et al. The risk of asthma in relation to occupational exposures: a casecontrol study from a Swedish city. Eur Respir J 1999; 13: 496-501.

5. Fishwick D, Pearce N, D'Souza W, et al. Occupational asthma in New Zealanders: a population based study. Occup Environ Med 1997; 54: 301-306.

6. Savonius B, Keskinen H, Tuppurainen M, Kanerva L. Occupational asthma caused by ethanolamines. Allergy 1994; 49: 877-881.

7. Burge S, Richardson MN. Occupational asthma due to indirect exposure to lauryl dimethyl benxyl ammonium chloride used in a floor cleaner. Thorax 1994; 49: 842-843.

8. Dijkman JH, Vooren PH, Kramps JA. Occupational asthma due to inhalation of chloramine-T. I. Clinical observations and inhalation-provocation studies. Int Arch Allergy Appl Immunol 1981; 64: 422-427.

9. Reijula K, Haahtela T, Klaukka T, Rantanen J. Incidence of occupational asthma and persistent asthma in young adults has increased in Finland. Chest 1996; 110: 58-61.

10. Haahtela T, Klaukka T. Societal and health care benefits of early use of inhaled steroids. Thorax 1998; 53: $1005-1006$.

11. Arinen S, Häkkinen U, Klaukka T, Klavus J, Lchtonen R, Aro S. Health and the use of health services in Finland. Main findings of the Finnish Health Care Survey 1995/96 and changes from 1987. Helsinki, Social Insurance Institution and National 
Research and Development Centre for Welfare and Health, 1998.

12. Rothman KJ, Greenland S. Modern Epidemiology. 2nd Edn. New York, Lippincott Raven, 1997.

13. Zock J-P, Kogevinas M, Sunyer J, et al. Asthma risk, cleaning activities and use of specific cleaning products among Spanish indoor cleaners. Scand J Work Environ Health 2001; 27: 76-81.

14. Pekkanen J, Pearce N. Defining asthma in epidemiological studies. Eur Respir J 1999; 14: 951-957.

15. Kogevinas M, Anto JM, Soriano JB, Aurello T, Burney P. The risk of asthma attributable to occupational exposures. A population-based study in Spain. Am J Respir Crit Care Med 1996; 154: 137-143.

16. Hemberg S. Introduction to occupational epidemiology. Chelsea, MI, Lewis Publishers, 1992.
17. Zock JP, Kogevinas M, Surtyer J, Antó JM, Burney P. Respiratory health in cleaning and office workers with asthma: suggestion of irritant induced asthma in cleaners. Eur Respir J 2000; 16: Suppl. 31, 520s.

18. Chang-Yeung M, Lam S, Kennedy S, Frew AL. Persistent asthma after repeated exposure to high concentrations of gases in pulpmills. Am J Resp Crit Care Med 1994; 149: 1676-1680.

19. Gautrin D, Bernstein IL, Brooks S. Reactive airways dysfunction syndrome, or irritant-induced asthma. In: Bernstein IL, Chan-Yeung M, Malo JL, Bernstein D, eds. Asthma in the Workplace, 2nd Edn. New York, Marcel Dekker, 1999; pp. 565-593.

20. $\mathrm{Xu} \mathrm{X}$, Christiani D. Occupational exposures and physician-diagnosed asthma. Chest 1993; 104: 1364 1370. 